\title{
Effects of Rhizopus Nigricans Exopolysaccharide on Proliferation, Apoptosis, and Migration of Breast Cancer MCF-7 Cells and Akt Signaling Pathway
}

\author{
Aizhai Xiang, ${ }^{1}$ Chen Ling, ${ }^{2}$ Wei Zhang, ${ }^{3}$ and Honggang Chen $\mathbb{D}^{1}$ \\ ${ }^{1}$ Department of Breast Surgery, Affiliated Hangzhou First People's Hospital, Zhejiang University School of Medicine, Hangzhou, \\ Zhejiang 310006, China \\ ${ }^{2}$ Department of Clinical Laboratory, The First Hospital of Jiaxing, Affiliated Hospital of Jiaxing University, Jiaxing, \\ Zhejiang 314000, China \\ ${ }^{3}$ Department of Breast Surgery, HwaMei Hospital, University of Chinese Academy of Sciences, Ningbo, Zhejiang 315010, China
}

Correspondence should be addressed to Honggang Chen; chenhg202011@163.com

Received 20 April 2021; Revised 6 June 2021; Accepted 14 June 2021; Published 25 June 2021

Academic Editor: Di Li

Copyright (C) 2021 Aizhai Xiang et al. This is an open access article distributed under the Creative Commons Attribution License, which permits unrestricted use, distribution, and reproduction in any medium, provided the original work is properly cited.

Objective. To study the effect of Rhizopus nigricans exopolysaccharide EPS1-1 on the proliferation, apoptosis, and migration of breast cancer MCF-7 cells. Methods. Human breast cancer MCF-7 cells were cultured in vitro and treated with different concentrations of EPS1-1. The effect of EPS1-1 on cell proliferation was tested by the CCK-8 experiment, and the effect of EPS1-1 on cell apoptosis was determined by flow cytometry. And the scratch test was used to detect the impact of EPS1-1 on cell migration. Western blot then was used to measure the expression changes of related proteins in the Akt signaling pathway. Results. Compared with the control group, treatment with EPS1-1 significantly reduced the proliferation, migration, and invasion ability of MCF-7 cells and promoted the apoptosis of MCF-7 cells in a dose-dependent manner. In terms of the underlying mechanism, EPS1-1 can significantly inhibit the phosphorylation of Akt at threonine 308 and serine 473 and cause the expression changes of downstream proliferation-related genes CCND1 and p21, apoptosis-related genes Bcl-2 and Bax, and migration-related genes Vimentin and E-cadherin in terms of their protein levels. Conclusion. EPS1-1 can inhibit the proliferation, migration, and invasion of breast cancer MCF-7 cells and promote the apoptosis of MCF-7 cells by inhibiting the activation of the Akt signaling pathway. Therefore, EPS1-1 can be used as a potential new drug or adjuvant drug for the treatment of breast cancer.

\section{Introduction}

Breast cancer (BC) is one of the most common and the leading cause of cancer-related death among women around the world [1]. Every year, a large number of cancer-related deaths are caused by BC [2]. Complex etiology including genetic factors and environmental factors, such as late age at birth, exogenous hormone intake, smoking, drinking and obesity, leads to the heterogeneity of $\mathrm{BC}$ [3]. Although advanced strategies including surgery, chemotherapy, radiotherapy, hormone therapy, and molecular targeted therapy have been widely used in $\mathrm{BC}$ treatment recent years, the prognosis of BC patients is still very poor [4]. Therefore, the development of new effective therapeutic drugs is a problem that needs to be solved urgently.

Biologically active polysaccharides have been widely studied and applied in the food and pharmaceutical industries due to their therapeutic properties and small side effects. The antitumor activity [5], immunomodulatory activity [6], and antibacterial activity [7] of polysaccharides have been well studied and applied in the fields of biochemistry and medicine. Yu et al. [8] extracted an extracellular polysaccharide, namely, EPS1-1 from the fermentation broth of Rhizopus nigricans. Studies have shown that EPS1-1 could significantly inhibit the tumor growth and increase the immune organs index of CT26 tumor-bearing mice. Also, EPS treatment 
increased the productions of interleukin-2 (IL-2) and tumor necrosis factor- $\alpha$ (TNF- $\alpha$ ) levels in serum, as well as increased the percentage of CD8(+) cytotoxic T cells among total spleen T lymphocyte [9]. EPS1-1 can also present antitumor activity and prolong the survival period of S180 tumor bearing mice [10]. Moreover, EPS1-1 can significantly enhance the body immunity through cellular immunity and humoral immunity by increasing the activities of phagocytosis and acid phosphatase and the production of NO, IL-2, and TNF- $\alpha$ [11]. These results indicate that EPS1-1 may become a new drug or adjuvant drug for tumor chemotherapy.

In this study, we extracted EPS1-1 from the fermentation broth of Rhizopus nigricans according to $\mathrm{Yu}$ [8] and studied its effect on the proliferation, apoptosis, and migration of breast cancer cell MCF-7 and the corresponding mechanism. Therefore, this study provides a theoretical basis for the clinical application of EPS1-1 as a new drug or auxiliary drug for the treatment of breast cancer.

\section{Materials and Methods}

2.1. Extraction and Identification of EPS1-1. The extraction of EPS1-1 followed the method reported by $\mathrm{Yu}$ et al. [8]. According to the results of high-performance liquid chromatography, EPS1-1 is composed of GLC, MAN, GAL, and FRU, with a polarity ratio of $5.89: 3.64: 3.20: 1.00$.

2.2. Cell Culture and Processing. The human breast cancer cell MCF-7 cell line and normal human breast epithelial cells (MCF-10A) were purchased from ATCC (United States) and cultured in DMEM medium containing $10 \%$ fetal bovine serum at $37^{\circ} \mathrm{C}$ and with $5 \% \mathrm{CO}_{2}$. The cells were then treated with the different concentration of EPS1-1 control $(0 \mu \mathrm{g} / \mathrm{mL})$ and treatment groups (including $200 \mu \mathrm{g} / \mathrm{mL}, 400 \mu \mathrm{g} / \mathrm{mL}, 600$ $\mu \mathrm{g} / \mathrm{mL}, 800 \mu \mathrm{g} / \mathrm{mL}$, and $1000 \mu \mathrm{g} / \mathrm{mL}$ in each treatment group).

2.3. CCK-8 Cell Proliferation Experiment. The CCK8 kit was purchased from Dojindo, Japan. MCF-7 cells were seeded in a 96-well plate with about 8,000 cells per well. After culturing in an incubator for $24 \mathrm{~h}$, the supernatant was removed, and the culture medium containing different concentrations of EPS1-1 was then added. After incubating for 24, 48, and $72 \mathrm{~h}, 10 \mathrm{ul}$ CCK8 reagent was then added to each well, and the cells were then continuously incubated in a $37^{\circ} \mathrm{C}$ incubator for an appropriate period. After that, a microplate reader was used to measure the absorbance at $450 \mathrm{~nm}$.

2.4. Colony Formation Assay. Cells were collected, counted, and seeded in a $6 \mathrm{~cm}$ culture plate. After 2 weeks of conventional culture, the cells were fixed with methanol at room temperature for 15 minutes and then stained with $1 \%$ crystal violet solution for 10 minutes to calculate the number of colonies.

2.5. Cell Scratch Test. The MCF-7 cells were seeded in a 6-well plate and cultured in an incubator until the cell fusion rate reaches $95 \%$. A pipette tip was used to draw a straight line with a width of $1 \mathrm{~mm}$ on the fused monolayer of cells in each well. The cells were washed 3 times with PBS, and a culture medium containing different concentrations of EPS1-1 was then added. After 0,48 , and $72 \mathrm{~h}$ of culture, the scratched area was photographed, and the cell migration rate was calculated.

2.6. Apoptosis Measured by Flow Cytometry. The MCF-7 cells were seeded in a 6 -well plate and cultured for $24 \mathrm{~h}$, then culture medium containing different concentrations of EPS1-1 was added, and cells were continuously cultured for 48 and $72 \mathrm{~h}$. A single-cell suspension after digestion with trypsin was then prepared, and according to the instructions, Annexin V-FITC/PI Apoptosis Kit (Sigma, USA) and flow cytometry were then used to detect the apoptosis rate.

2.7. Transwell Assay. The Transwell test was performed on the $8.0 \mu \mathrm{m}$ Transwell plate with matrix gel (Corning, USA). The cells were resuspended in $200 \mu \mathrm{L}$ serum-free DMEM medium and added to the upper chamber of Transwell. $600 \mu \mathrm{L}$ DMEM medium containing $10 \%$ FBS was added to the lower chamber. After 24 hours of culture, the submembranous cells were fixed with methanol at room temperature for 10 minutes and stained with $0.1 \%$ crystal violet solution for 15 minutes to calculate cell number.

2.8. Western Blot. The MCF-7 cells were seeded in a 6-well plate and cultured for $24 \mathrm{~h}$, and then, a culture medium containing different concentrations of EPS1-1 was added, and cells were continuously cultured for $72 \mathrm{~h}$. The protein was extracted with RIPA lysis buffer, and the protein concentration was determined by the BCA method. $20 \mu \mathrm{g}$ protein sample was added to each well for electrophoresis, followed by transferring the protein to the membrane, blockage of the membrane, and incubations with primary and secondary antibodies before the development of the image. All the antibodies used in this experiment were purchased from Abcam, USA.

2.9. Statistical Analysis. SPSS 19.0 statistical software was used for data analysis. The results were expressed as mean \pm standard deviation $(x \pm s)$. The difference between the groups was analyzed with Student's $t$-test or one-way analysis of variance. Each experiment was repeated at least three times, and $P<0.05$ indicated that the difference was statistically significant.

\section{Results}

3.1. The Effect of EPS1-1 on the Proliferation of MCF-7 Cells. As shown in Figure 1(a), compared with the control group, EPS1-1 significantly reduced the proliferation activity of MCF-7 cells in a dose-dependent manner. The inhibitory effect at $48 \mathrm{~h}$ and $72 \mathrm{~h}$ was statistically different (IC50 $=387.1$ and 357.2, respectively), and when the concentration was greater than $600 \mu \mathrm{g} / \mathrm{mL}$, the proliferation activity of MCF-7 cells did not decrease significantly. Therefore, $48 \mathrm{~h}$ and $72 \mathrm{~h}$ were used as the treatment time in the follow-up test, and the concentration of EPS1-1 was ranged from 0 to $600 \mu \mathrm{g} / \mathrm{mL}$. We also found that when the concentration was less than $600 \mu \mathrm{g} / \mathrm{mL}$, EPS1-1 showed no significant toxicity to MCF-10A cells (Figure 1(b)). As shown in Figure 1(c), compared with the control group, EPS1-1 also significantly 


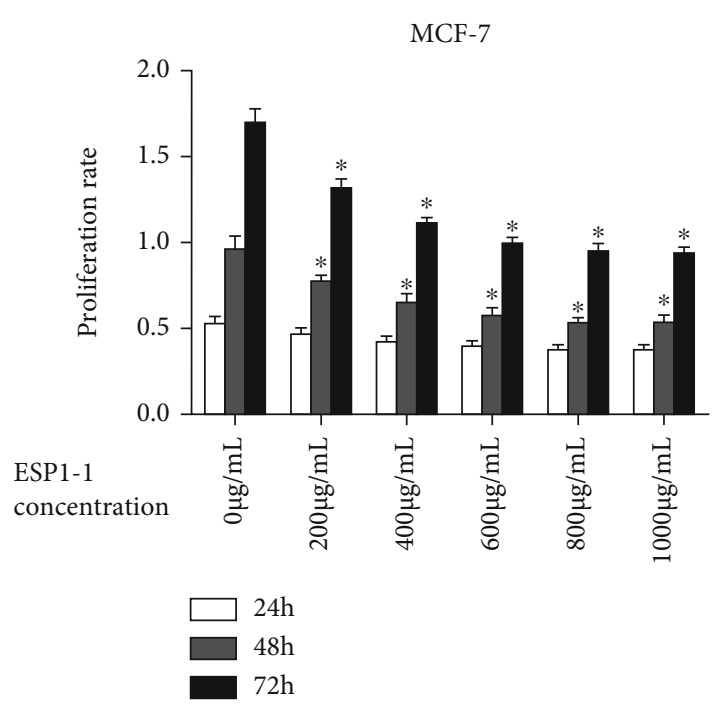

(a)

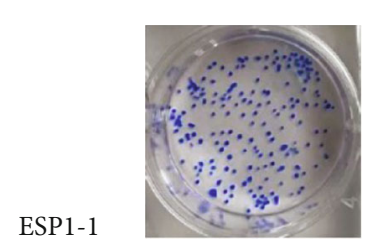

concentration $0 \mu \mathrm{g} / \mathrm{mL}$

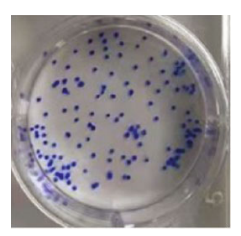

$200 \mu \mathrm{g} / \mathrm{mL}$

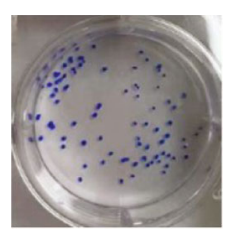

$400 \mu \mathrm{g} / \mathrm{mL}$

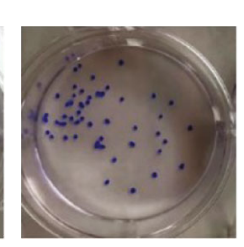

$600 \mu \mathrm{g} / \mathrm{mL}$

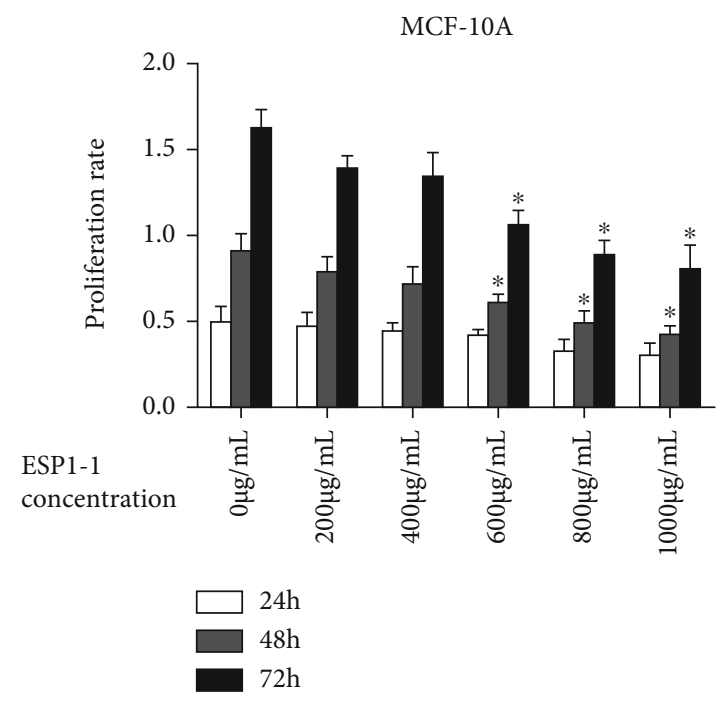

(b)

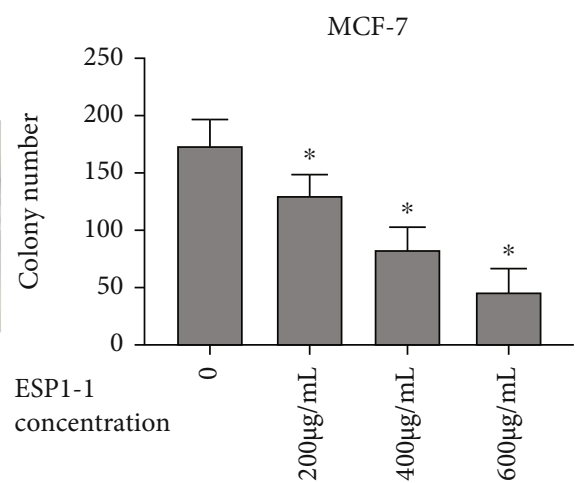

(c)

FIgURE 1: The effect of EPS1-1 on the proliferation activity of MCF-7 cells, $N=3,{ }^{*} P<0.05$.

reduced the cell colony formation activity of MCF-7 cells in a dose-dependent manner.

3.2. The Effect of EPS1-1 on the Apoptosis of MCF-7 Cells. As shown in Figure 2, compared with the control group, after EPS1-1 treatment for $48 \mathrm{~h}$ and $72 \mathrm{~h}$, the apoptotic ratio of MCF-7 cells increased significantly in a dose-dependent manner $(P<0.05)$. The above results indicate that EPS1-1 can promote the apoptosis of MCF-7 cells.

3.3. Effect of EPS1-1 on the Migration of MCF-7 Cells. As shown in Figure 3, compared with the control group, after $48 \mathrm{~h}$ and $72 \mathrm{~h}$ of EPS1-1 treatment, the closure ratio of MCF-7 cell scratches decreased significantly and showed a dose-dependent manner $(P<0.05)$, therefore indicating that EPS1-1 can inhibit the migration of MCF-7 cells.

3.4. Effect of EPS1-1 on the Invasion of MCF-7 Cells. As shown in Figure 4, compared with the control group, after $48 \mathrm{~h}$ of EPS1-1 treatment, the invasion ability of MCF-7 cell decreased significantly and showed a dose-dependent manner $(P<0.05)$, therefore indicating that EPS1-1 can inhibit the invasion of MCF-7 cells.
3.5. The Impact of EPS1-1 on Akt Signal Pathway. After $72 \mathrm{~h}$ of treatment of MCF-7 cells with EPS1-1, we found that, compared with the control group, EPS1-1 can significantly inhibit the phosphorylation of Akt at threonine (Thr) 308 and serine (Ser) 473 (see Figure 4). We also detected the protein expression involved in the downstream of Akt signaling pathway including proliferation-related genes CCND1 and p21, apoptosis-related genes Bcl-2 and Bax, and migrationrelated genes Vimentin and E-cadherin and found that the expression levels of these genes were affected by the treatments of EPS1-1 (see Figure 5).

\section{Discussion}

Natural polysaccharides have attracted widespread attention due to their medicinal value, especially in the treatment of cancer. Many polysaccharides in plants, fungi, algae, and bacteria can inhibit the occurrence and development of cancer, such as liver cancer, breast cancer, lung cancer, and colon cancer. In this study, we extracted EPS1-1 from the fermentation broth of Rhizopus nigricans and studied its action and mechanism in the inhibition of breast cancer cells.

Functional assays showed that EPS1-1 can inhibit different perspective of the MCF-7 cells, specifically, we found that 

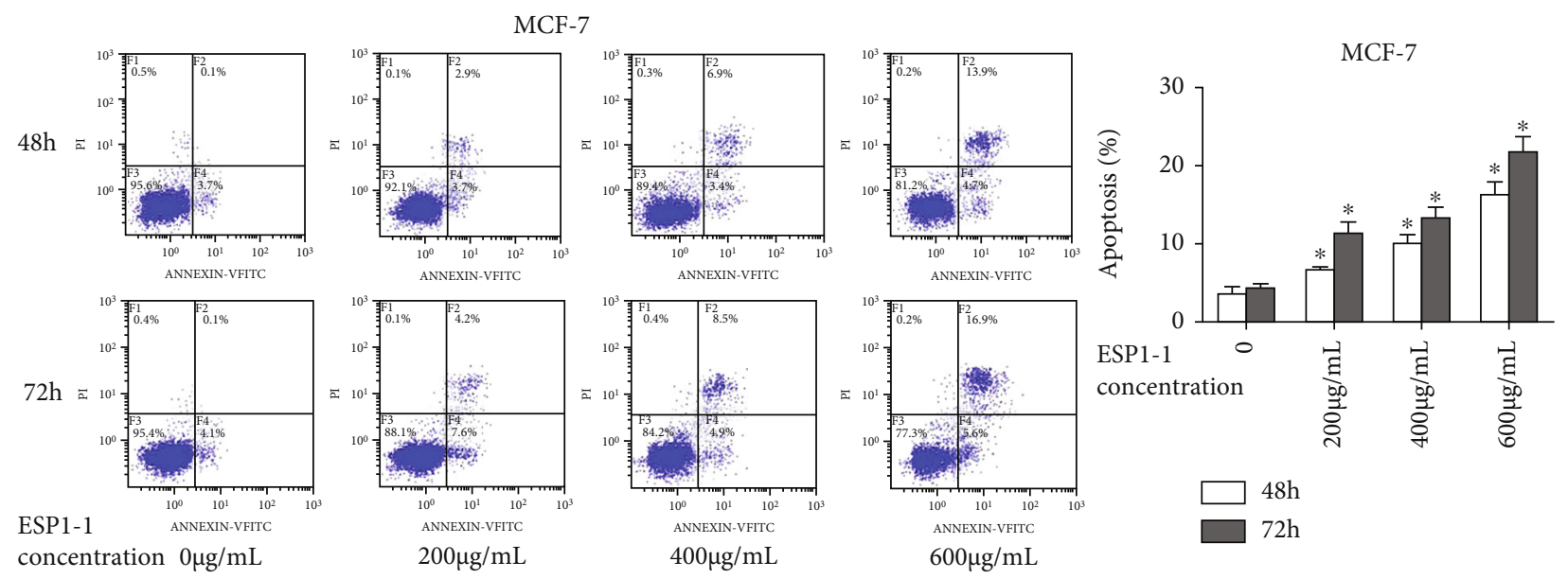

ESP1-1
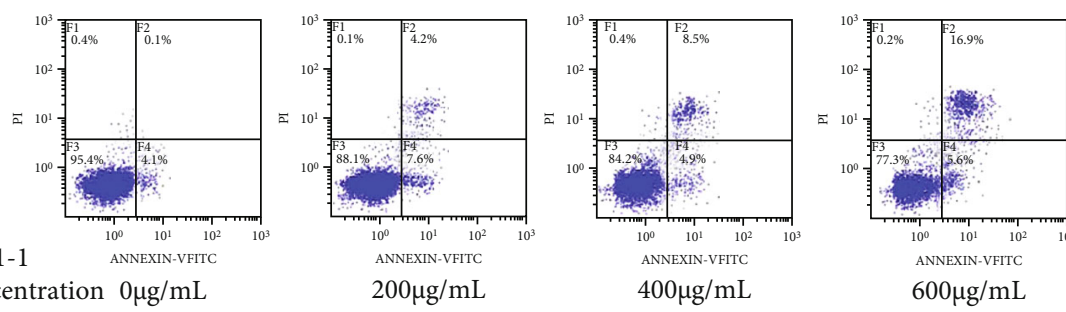

Figure 2: The effect of EPS1-1 on the apoptosis of MCF-7 cell, $N=3,{ }^{*} P<0.05$.

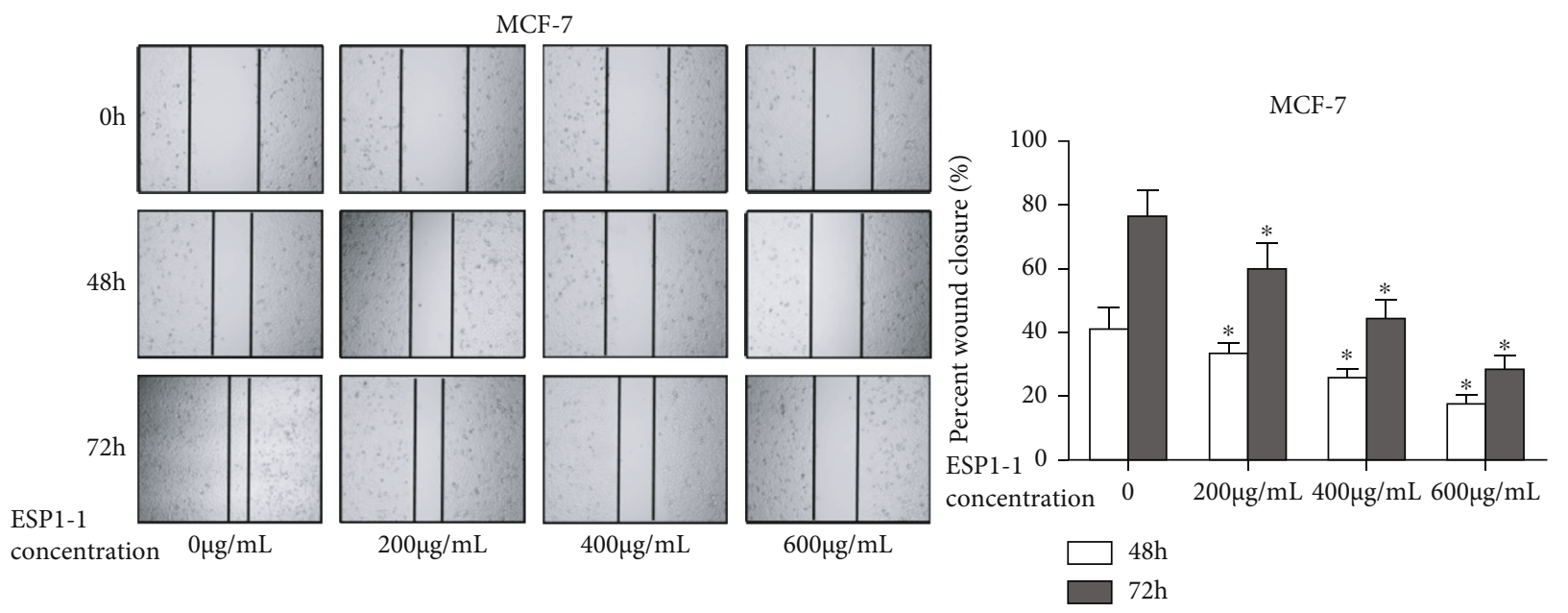

FIgURE 3: The effect of EPS1-1 on the migration of MCF-7 cells, $N=3,{ }^{*} P<0.05$.

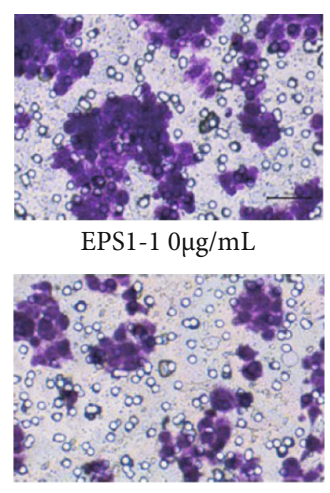

EPS1-1 $400 \mu \mathrm{g} / \mathrm{mL}$

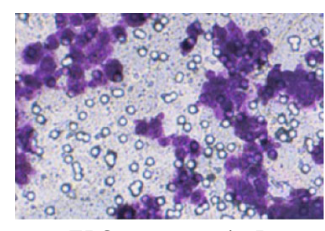

EPS1-1 $200 \mu \mathrm{g} / \mathrm{mL}$

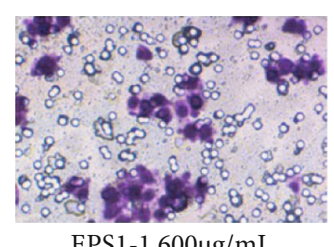

MCF-7

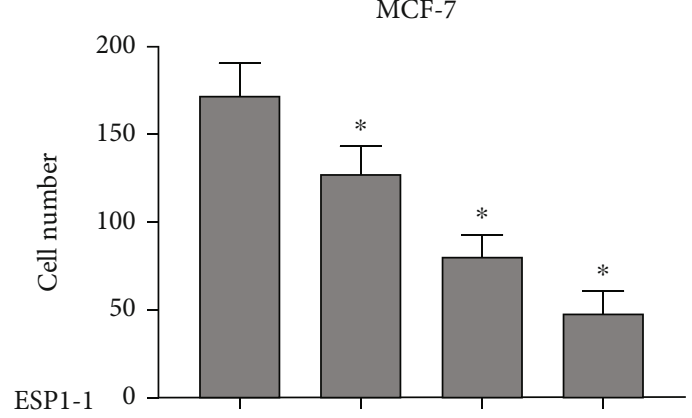

concentration $0 \mu \mathrm{g} / \mathrm{mL} \quad 200 \mu \mathrm{g} / \mathrm{mL} 400 \mu \mathrm{g} / \mathrm{mL} 600 \mu \mathrm{g} / \mathrm{mL}$

FIgure 4: The effect of EPS1-1 on the invasion of MCF-7 cells, $N=3,{ }^{*} P<0.05$.

EPS1-1 can inhibit the proliferation of MCF-7 cells through the CCK8 experiment and colony formation assay. Moreover, we showed that EPS1-1 can promote the apoptosis of MCF-7 cells via flow cytometry and inhibit MCF-7 cell migration and invasion via the scratch experiment and Transwell assay. Therefore, our results show that in breast cancer cells, EPS1-1 has obvious tumor suppressor activity, and has the potential to be used as a new drug or auxiliary 

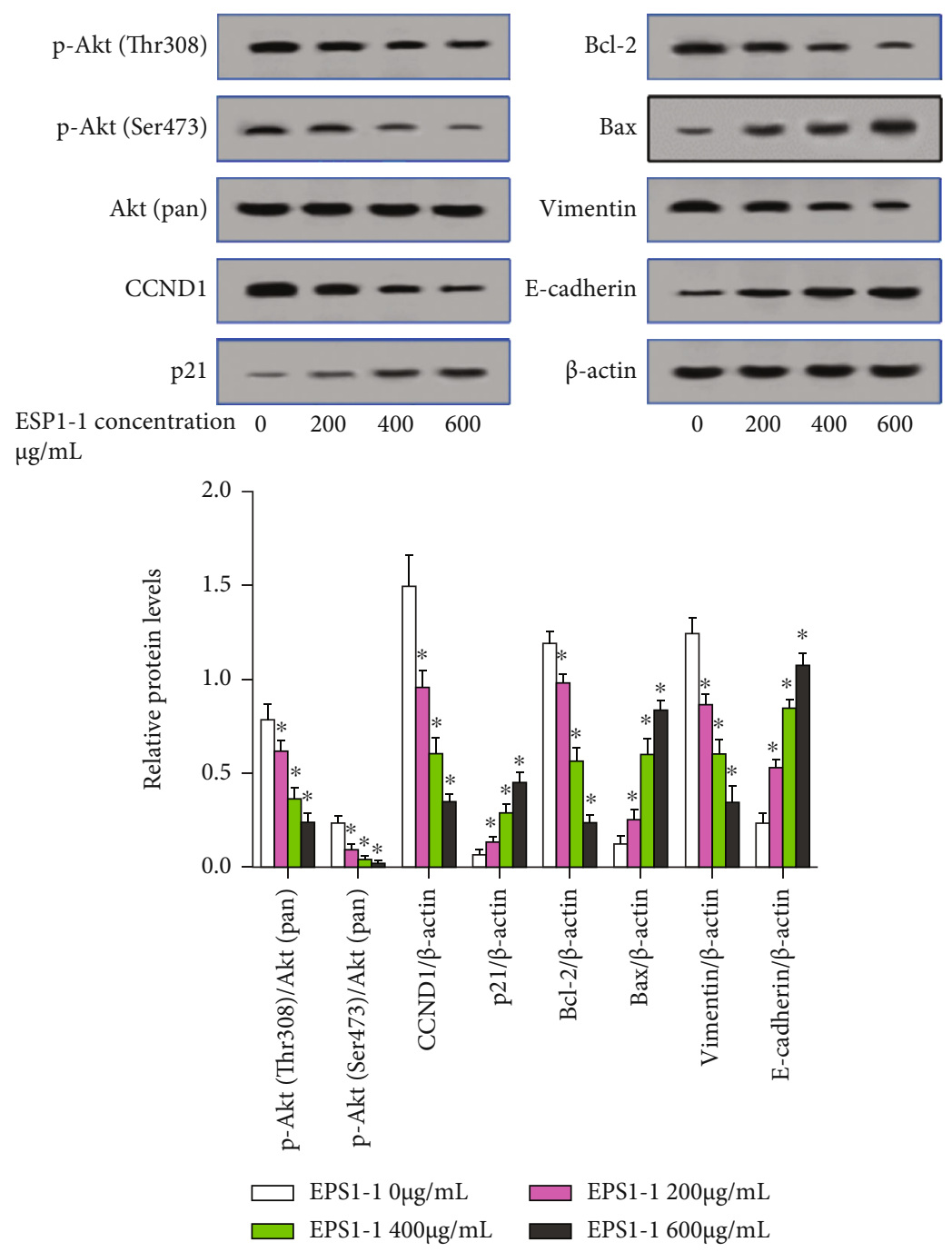

FIgUre 5: The effect of EPS1-1 on Akt signaling pathway and its downstream genes, $N=3,{ }^{*} P<0.05$.

drug in the treatment of breast cancers. Therefore, the anticancer role of EPS1-1 in breast cancer is the same as that in other tumors previously reported [8-13].

Previous studies have investigated the mechanisms of EPS1-1 in anticancer application. On the one side, EPS1-1 may increase the productions of interleukin-2 (IL-2) and tumor necrosis factor- $\alpha$ (TNF- $\alpha$ ) levels in serum, as well as increased the percentage of CD8(+) cytotoxic T cells among total spleen T lymphocyte [9]. In addition, EPS1-1 can significantly enhance the body immunity through cellular immunity and humoral immunity by increasing the activities of phagocytosis and acid phosphatase and the production of NO, IL-2, and TNF- $\alpha$ [11]. Herein, we found that EPS1-1 can inhibit the activation of the Akt signaling pathway. The serine/threonine kinase Akt (also known as protein kinase $\mathrm{B}$ or $\mathrm{PKB}$ ) is a protooncogene that plays an important role in regulating various cell functions including metabolism, proliferation, apoptosis, migration, and protein synthesis. Phosphorylation of threonine 308 of Akt can cause partial activation of Akt, and serine 473 phosphorylation can stimulate the complete enzymatic activity of Akt [14]. We found that EPS1-1 can inhibit the phosphorylation of Akt at these two sites. CCND1 [15] and p21 [16] are factors related to cell proliferation downstream of Akt. We found that after EPS1-1 treatment, the expression of CCND1 was significantly reduced, while the expression of p21 was significantly increased. CCND1 can promote cell proliferation, while p21 inhibits cell proliferation, the contrasting responses of these two genes upon the EPS1-1 treatment explains the inhibitory effect of EPS1-1 on MCF-7 cell proliferation. Bcl2 and Bax are factors related to apoptosis downstream of Akt [17]. Our results show that after EPS1-1 treatment, the expression of $\mathrm{Bcl}-2$ was significantly reduced, while the expression of Bax was significantly increased. Bcl-2 can inhibit cell apoptosis, while Bax promotes cell apoptosis, which explains the apoptosis-promoting effect of EPS1-1 on MCF-7 cells. Vimentin and E-cadherin are factors related to cell migration downstream of Akt [18]. We found that after EPS1-1 treatment, the expression of Vimentin was significantly reduced, while the expression of E-cadherin was significantly increased. Vimentin can promote cell migration, while E-cadherin inhibits cell migration, which explains the 
inhibitory effect of EPS1-1 on MCF-7 cell migration. In summary, EPS1-1 inhibits the proliferation and migration of MCF-7 cells by inhibiting the activation of the Akt signaling pathway and promotes the apoptosis of MCF-7 cells, which explains the anticancer mechanism of EPS1-1 on the molecular level.

This study lacks animal experiments and clinical experiments and only explored the potential value and theoretical basis of EPS1-1 as a cancer suppressor, so it has certain limitations.

\section{Conclusion}

In this study, EPS1-1 was extracted from the fermentation broth of Rhizopus nigricans, and in vitro experiments confirmed that EPS1-1 can inhibit the proliferation, migration, and invasion of breast cancer MCF-7 cells by inhibiting the activation of the Akt signaling pathway and can promote the apoptosis of MCF-7 cells. Therefore, this study provides a theoretical basis for the clinical application of EPS1-1 as a new drug or auxiliary drug for the treatment of breast cancer.

\section{Data Availability}

All data generated or analyzed during this study are included in this published article.

\section{Conflicts of Interest}

The authors declare that they have no conflicts of interest.

\section{Acknowledgments}

This work was supported by the Zhejiang Provincial Natural Science Foundation of China (No. LQ20H160017) and the 2019 Jiaxing Key Discipline of Medicine-Clinical Laboratory Diagnostics (Innovation Subject 2019-cx-03).

\section{References}

[1] A. M. Gonzalez-Angulo, F. Morales-Vasquez, and G. N. Hortobagyi, "Overview of resistance to systemic therapy in patients with breast cancer," Advances in Experimental Medicine and Biology, vol. 608, pp. 1-22, 2007.

[2] A. Jemal, R. Siegel, E. Ward, Y. Hao, J. Xu, and M. J. Thun, "Cancer statistics, 2009," CA: A Cancer Journal for Clinicians, vol. 59, no. 4, pp. 225-249, 2009.

[3] J. Yao, F. Xu, D. Zhang et al., "TP73-AS1 promotes breast cancer cell proliferation through miR-200a-mediated TFAM inhibition," Journal of Cellular Biochemistry, vol. 119, no. 1, pp. 680-690, 2018.

[4] A. C. P. Ribeiro Pereira, R. J. Koifman, and A. Bergmann, "Incidence and risk factors of lymphedema after breast cancer treatment: 10 years of follow-up," Breast, vol. 36, pp. 67-73, 2017.

[5] K.-F. Wang, K.-y. Sui, C. Guo, and C.-Z. Liu, "Improved production and antitumor activity of intracellular proteinpolysaccharide from Trametes versicolor by the quorum sensing molecule-tyrosol," Journal of Functional Foods, vol. 37, pp. 90-96, 2017.
[6] W. Fan, P. Zheng, Y. Wang, P. Hao, J. Liu, and X. Zhao, “Analysis of immunostimulatory activity of polysaccharide extracted from Yu-Ping-Feng in vitro and in vivo," Biomedicine \& Pharmacotherapy, vol. 93, pp. 146-155, 2017.

[7] Y. Ma, C. Liu, D. Qu, Y. Chen, M. Huang, and Y. Liu, "Antibacterial evaluation of sliver nanoparticles synthesized by polysaccharides from Astragalus membranaceus roots," Biomedicine \& Pharmacotherapy, vol. 89, pp. 351-357, 2017.

[8] W. Q. Yu, G. C. Chen, P. Y. Zhang, and K. S. Chen, "Purification, partial characterization and antitumor effect of an exopolysaccharide from Rhizopus nigricans," International Journal of Biological Macromolecules, vol. 82, pp. 299-307, 2016.

[9] L. Zhu, J. F. Cao, G. C. Chen et al., "Anti-tumor and immunomodulatory activities of an exopolysaccharide from Rhizopus nigricans on CT26 tumor-bearing mice," International Immunopharmacology, vol. 36, pp. 218-224, 2016.

[10] J. F. Cao, D. Hou, J. B. Lu et al., "Anti-tumor activity of exopolysaccharide from Rhizopus nigricans Ehrenb on S180 tumorbearing mice," Bioorganic \& Medicinal Chemistry Letters, vol. 26, no. 8, pp. 2098-2104, 2016.

[11] Z. D. Yu, M. L. Kong, P. Y. Zhang, Q. J. Sun, and K. S. Chen, "Immune-enhancing activity of extracellular polysaccharides isolated from Rhizopus nigricans," Carbohydrate Polymers, vol. 148, pp. 318-325, 2016.

[12] G. Chu, Y. Miao, K. Huang, H. Song, and L. Liu, "Role and mechanism of Rhizopus nigrum polysaccharide EPS1-1 as pharmaceutical for therapy of hepatocellular carcinoma," Frontiers in Bioengineering and Biotechnology, vol. 8, p. 509, 2020.

[13] Y. Lu, X. Zhang, J. Wang, and K. Chen, "Exopolysaccharides isolated from Rhizopus nigricans induced colon cancer cell apoptosis in vitro and in vivo via activating the AMPK pathway," Bioscience Reports, vol. 40, no. 1, 2020.

[14] R. Chen, O. Kim, J. Yang et al., "Regulation of Akt/PKB activation by tyrosine phosphorylation," The Journal of Biological Chemistry, vol. 276, no. 34, pp. 31858-31862, 2001.

[15] Y. Feng, W. Qian, Y. Zhang et al., "CDCA2 promotes the proliferation of colorectal cancer cells by activating the AKT/CCND1 pathway in vitro and in vivo," BMC Cancer, vol. 19, p. 576, 2019.

[16] L. Zhang, R. Lian, J. Zhao et al., "IGFBP7 inhibits cell proliferation by suppressing AKT activity and cell cycle progression in thyroid carcinoma," Cell \& Bioscience, vol. 9, p. 44, 2019.

[17] T. Okada, B. Enkhjargal, Z. D. Travis et al., "FGF-2 attenuates neuronal apoptosis via FGFR3/PI3k/Akt signaling pathway after subarachnoid hemorrhage," Molecular neurobiology, vol. 56, no. 12, pp. 8203-8219, 2019.

[18] M. M. Nijkamp, P. N. Span, H. Stegeman, R. Grénman, J. H. Kaanders, and J. Bussink, "Low phosphorylated AKT expression in laryngeal cancer: indications for a higher metastatic risk," International Journal of Radiation Oncology, Biology and Physics, vol. 87, pp. 349-355, 2013. 